\title{
Ecosystems, Design, and Glocalization: A multi-level study of Technovation
}

\author{
Jasmine A. Shaw \& Steven M. Muegge
}

\author{
"Business ecosystems form around problems to solve and pain to soothe."
}

James F. Moore

Management scientist, coined "business ecosystems"

\begin{abstract}
Business ecosystems are an increasingly prominent organizational form in both management research and practice. A growing body of research exists about ecosystem design, but designing local ecosystem instances within a global ecosystem is not yet well understood or defined. This article contributes a multilevel, embedded case study of the global and local ecosystems anchored around the Technovation Girls competition - the world's largest technology entrepreneurship challenge for girls. We first define the process platform driving this ecosystem and anchoring the local instances. Second, we identify key architectural properties of a global-local ecosystem. Lastly, we specify a process for defining design rules in an organizational setting. In addition to theoretical relevance for ecosystem scholarship, our results are also of practical relevance to leaders of existing or nascent global ecosystems, who may benefit from techniques described in this paper that involve designing a flexible global ecosystem architecture that accommodates local variation.
\end{abstract}

\section{Introduction}

Business ecosystems are prominent in both theory and practice. What began as an ecological metaphor (Moore, 1993) has now become an organizational form (Moore, 2006) for the complex social systems that drive product development, innovation, and new venture creation (Adner, 2017; Muegge \& Mezen, 2017; Kapoor, 2018; Muegge et al. 2018). Nonetheless, much work yet remains. Ecosystems as organizational forms for social impact through non-profit organizations have not received much attention, while the structures of global ecosystems with local embedded instances remain largely or entirely unexamined.

To explore how local variants of a global ecosystem are designed, this study brings together two management constructs from adjacent streams of management research. First, we look at design rules, as enforced system parameters that preside at the highest level of a system's architecture (Baldwin \& Clark, 2000). These parameters "affect other parameter choices but they themselves cannot be changed". Second is glocalization, which describes the co-developing and mutually reinforcing interactions between global and local entities (Drori et al., 2014). According to glocalization theory, organizations face the "simultaneity and timreview.ca interdependence of particularizing and universalizing tendencies", with the global tending towards "universal", and the local tending towards "particular".

Business ecosystem research has contributed multiple frameworks, with no single framework yet emerging as dominating discourse. For example, the multisided platform perspective has been used to characterize the Lead to Win (Bailetti \& Bot, 2013; Sunna, 2016; Muegge \& Mezaen, 2017) and Intel (Gawer \& Cusumano, 2014) ecosystems. Adner (2017) developed a structural framework to identify the interdependent connections between actors in an ecosystem. Integrating several dimensions from the literature, Rong et al. (2015) constructed a "6C" framework, and applied it to companies engaged in the Internet-of-Things ecosystem. Others describe ecosystems as "multi-level systems" (Muegge, 2011a; Muegge, 2013).

Within this body of research, scholars have identified the need to extend their focus beyond a single ecosystem perspective. This study thus attempts to close two knowledge gaps. First, this is the lack of understanding of the multi-level architecture of embedded ecosystems (Radziwon \& Bogers, 2019). Second, this is the lack of knowledge on the application of process platforms in 


\section{Ecosystems, Design, and Glocalization: A multi-level study of Technovation}

\section{Jasmine A. Shaw \& Steven M. Muegge}

different field settings (Muegge et al., 2018), that is, "mission-driven" rather than "product-driven" ecosystems.

This research examines the network of individuals and organizations anchored around Technovation (https://www.technovation.org/), a non-profit education technology organization. Technovation's flagship program, Technovation Girls (https://technovationchallenge.org/), is the world's largest technology entrepreneurship competition for girls. We address the following research questions: What is Technovation, and can it be described using frameworks from the business ecosystem literature? and What are the design rules for local Technovation chapters? Our case study encompasses six local Technovation chapters three in Canada, and three in Mexico - operating under the umbrella of the non-profit parent organization. As the country of residence of both researchers, Canada was chosen for both familiarity and access to key informants. Mexico was chosen for theoretical replication: its cultural dimensions vary widely from Canada's, and their Technovation program is structured differently at the national level.

Technovation was chosen as the field setting for three reasons. First, it is a novel organizational setting. Rather than creating new ventures or innovative products, Technovation leverages the ecosystem setting to create intangible social goods such as entrepreneurial opportunity and self-efficacy. Second, it is an exemplary case. Since its inception, over 25,000 students have participated in the Technovation Girls program. Third, gender equity is a United Nations Sustainable Development Goal (https://sdgs.un.org/goals/goal5) that is front and centre on the global stage. Furthermore, in the Science, Technology, Engineering, and Math (STEM) domain, there is an even greater disparity of female representation. In 2014, a paltry $19 \%$ of engineering students in Canada were women (Natural Sciences and Engineering Research Council of Canada, 2017).

There are three primary contributions of this research. First is specification of the global Technovation ecosystem. Explicitly articulating the components and processes of a program designed to empower girls through technology entrepreneurship can support other organizations striving towards the same goal. Second is an exploration of the architectural properties of a "glocal" ecosystem. Third is a process to specify design rules for an organization and provide representative examples. This process can be directly applied by managers seeking to bound the variation and adaptation of local subsidiaries.

This article is organized into six sections. Section 2 presents key information from prior studies on business ecosystems, design science and design rules, and glocalization. Section 3 describes the research method used. Section 4 presents the research results, which are further elaborated in Section 5. Section 6 concludes with key insights and opportunities for future research.

\section{Literature Review}

This literature review summarizes and interprets prior research on business ecosystems, glocalization, and design rules.

\section{Business ecosystems}

Business ecosystem research initially stemmed from a biology-based ecological metaphor: a firm as an entity whose "survival" is determined by its "co-evolution" with fellow species such as suppliers, partners, customers, and competitors, to name a few (Moore, 1993). Within a business ecosystem, these entities have complex, interdependent relationships, that includes both competing and collaborating with one another to achieve a shared purpose (Moore, 2013) or focal value proposition (Adner, 2017; Kapoor, 2018). In contrast with biology-based ecosystems, in technology-based business ecosystems the shared purpose is driven by "a set of values about openness of ideas and technologies" (Moore, 2013).

In a recent article exploring previous research in this domain, Kapoor (2018) distilled the core elements of a business ecosystem into actors, activities, and architectures. Each is explored below in further detail. Actors are the entities who participate in shaping the ecosystem's shared purpose. While early studies equated actors to firms (Moore, 1993; Iansiti \& Levien, 2004), recent literature has acknowledged that the ecosystem construct extends beyond the product development space. These new perspectives encompass actors such as universities, and economic development agencies, as well as individuals. Regardless of who they are, participation within an ecosystem involves interdependence, meaning that each actor's individual contributions "share in some large measure the outcome of the whole ecosystem" (Muegge, 2011a). A leader or keystone player (Iansiti \& Levien, 2004) often emerges to develop the overall vision and strategy for the ecosystem. 


\section{Ecosystems, Design, and Glocalization: A multi-level study of Technovation}

\section{Jasmine A. Shaw \& Steven M. Muegge}

Activities are the "discrete actions to be undertaken in order for the value proposition to materialize" (Adner, 2017). For entrepreneurial ecosystems, incubation and acceleration (Colombelli et al., 2017) and providing capital funding (Bailetti \& Bot, 2013) are key contributions. Meanwhile, in a traditional business ecosystem, delivering a specialized technology or defining a technological solution architecture are common contributions (Iansiti \& Levien, 2004).

Last is the ecosystem's architecture, which defines the structural configuration of actors and activities required to achieve a shared purpose. Simply put, it is what "connect[s] offers and actors" (Kapoor, 2018). In addition to the existence of an architecture, Adner (2017) argues that actors must agree on their relative position within this configuration. Agreement by all actors creates alignment, which in turn reduces the risks associated with ecosystem-driven development. Another key feature impacting architecture is the anchor: a technical, organizational, or social entity connecting actors in the ecosystem, and often responsible for forming its boundaries (Muegge, 2011b)

Ecosystem architecture has been represented by multiple frameworks. One of the most common representations is the multisided platform. A platform is "a set of technological building blocks and complementary assets that companies and individuals can use and consume to develop complementary products, technologies, and services" (Muegge, 2011a). A multisided platform is a configuration of stakeholders, or sides, who transact through the platform. An alternative architectural representation is the multi-level system, comprised of three organizational levels: an ecosystem, community, and platform (Muegge, 2013; Muegge \& Mezen, 2017). Yet another perspective is governance design, which considers networks of actors, that exchange information and enable learning processes (Colombelli et al., 2017).

Applications of the ecosystem construct have expanded well beyond the original realm of product development. However, ecosystems anchored by a non-profit organization, whose shared purpose is social good, have yet to be studied empirically. To characterize the focal organization of our study, we selected the multisided platform perspective, for two reasons. First, our initial review of Technovation's organizational structure revealed several stakeholder groups, which suggested the presence of "sides". Second, it has been successfully used to characterize "non-traditional" ecosystems, such as those anchored by venture-creation processes.

\section{Design}

Consistent with prior work on ecosystem design by Muegge et al. (2018), our research positions business ecosystems as design artifacts. In general, artifacts have an architecture comprised of components (Simon, 1962). The components may be nested within other components or arranged horizontally at the same level. This structural arrangement is called a hierarchy. When components are organized such that there is interdependence within and independence across (Baldwin \& Clark, 2000), the design is considered modular. According to Parnas (1972), modularity can be achieved through information hiding, whereby each module possesses "knowledge of a design decision which it hides from all others".

A modular design is key to the growth of platforms because it increases potential for complementary innovation (Gawer \& Cusumano, 2014). With clearly defined interfaces, modules can easily be swapped in and out of the platform. Additional modules increase traffic through the platform, thus increasing its value through network effects. Modularity is also a prerequisite condition for option value, "the right but not the obligation to choose a course of action" (Baldwin \& Clark, 2006). In the context of a platform, option value allows complementors the opportunity to plug in their module without undercutting the functionality of the system as a whole.

In a modular system, design rules are parameters which preside at the highest level of the system -that is, they represent visible information (Baldwin \& Clark, 2000). By converting an ordinary design parameter into a design rule, interdependency gets replaced with hierarchy. Iterative design which would normally occur in an interdependent structure is now governed by a fixed parameter. Although new design rules may emerge as interdependencies become apparent, rescinding design rules well into the design process can be costly, because these rules impact all lower-level modules. As such, the architects who specify design rules often have first-hand experience working with complex systems, which helps them to anticipate latent interdependencies.

Baldwin and Clark, define three types of design rules: architectural, which specify "what modules will be part of the system, and what their roles will be"; interface, which specify "descriptions of how the different modules will interact"; and integration, or "procedures that will allow designers to assemble the system and determine how well it works" (2000). 


\section{Ecosystems, Design, and Glocalization: A multi-level study of Technovation}

\section{Jasmine A. Shaw \& Steven M. Muegge}

The design rules construct is inherently multi-level. It describes "global" parameters that influence the design of "local" modules. The points of similarity between design rules and glocalization, as seen in the next stream below, are central to our subsequent analysis.

\section{Glocalization}

Our review of the business ecosystem literature located no studies that had examined the instantiation of regional instances within a global ecosystem. Thus, we turned to the glocalization literature to explore the underlying theoretical constructs of multinational organizations.

Robertson (1995) presented glocalization as an alternative theoretical perspective to globalization. He argued that the "debate about global homogenization versus heterogenization should be transcended". Rather, glocalization stipulates that global and local phenomena co-exist and influence one another. Drori et al. (2014) also argued that, in practice, the universalityparticularity dichotomy is insufficient: "Multinational organizations wrestle with matters of identity and of operations that are simultaneously global and local". Thus, real-life decisions cannot be categorized as one or the other: real decisions fall somewhere between.

In the transfer from global to local, designed artifacts pass through an adaptation process to bring them into alignment with local values and culture. This recontextualization does not completely sever the localized form from its global ancestor. It retains a "family resemblance with all the other localized variants that accounts for the underlying universalizing dimension" (Meyer, 2014). Subsidiaries are instances of a multinational corporation that make up the system (organization) as a whole. Similarly, modules are complementary, unique units of a platform.

\section{Method}

Our research followed Yin's (2018) case study method, employing an embedded, multi-level design. The context was the 2020 Technovation Girls season (a fourmonth long competition), and the phenomena were 7 cases: 1 global non-profit organization along with 6 local chapters. The chapters were based in Ottawa (Canada), Montréal (Canada), Calgary (Canada), Guadalajara (Mexico), Mexico City (Mexico), and Mérida (Mexico). To describe and explain the design of local ecosystems operating within the context of a global technology entrepreneurship competition for girls, we used the techniques of previous studies for mapping business ecosystems (Mezen, 2014; Sunna, 2016), in particular the multisided platform representation (Table 1).

Data collection was carried out by the first author between January and May 2020. This included interviews with 26 stakeholders: global stakeholders included employees and Board of Directors members, while local stakeholders included regional ambassadors, a subset of volunteers (mentors, judges, and instructors), and representatives from partner organizations. Direct observation and participant-observation included Technovation events: orientation meetings, workshops, competitions. Archival sources included online news publications and social media postings from each of the six local chapters, the Technovation website, including the Technovation Girls FAQ (https://iridescentsupport.zendesk.com/hc/en-

us/categories/115000091348-Technovation-Girls), and a documentary film about the Technovation Girls

Table 1. Multisided platform ecosystem framework

\begin{tabular}{lll}
\hline Feature & Explanation offeature & Sources \\
\hline Sides & Platform sides & Muegge et al. (2018) \\
& Characteristics of side & Sunna (2016) \\
Platform & Processes & \\
& Components/sub-components & \\
Controls & $\begin{array}{l}\text { Contractual terms of direct } \\
\text { interaction } \\
\text { Openness } \\
\text { Desired outcomes }\end{array}$ & \\
& Membership rules for each side & \\
& System-level objectives & \\
\hline
\end{tabular}




\section{Ecosystems, Design, and Glocalization: A multi-level study of Technovation}

\section{Jasmine A. Shaw \& Steven M. Muegge}

Table 2. Multisided platform representation of Technovation

\begin{tabular}{ll}
\hline Feature & Technovation Global explanation of features \\
\hline Sides & - 10 sides defined in Table 3 \\
& - Contributions and expected benefits defined in Table 3 \\
Platform & - A cyclical process shown in Figure 1 \\
& - 6 components and 19 sub-components defined in Table 4 \\
Controls & - Some transactions are mediated through Technovation digital \\
& - platform \\
& - Global organization does not constrain interactions of local actors \\
& - Increased self-efficacy in participants \\
Desired & - Participants electing to pursue studies in STEM disciplines \\
\hline
\end{tabular}

competition (http://www.codegirlmovie.com/).

Our analytic strategies were cross-case comparison (Eisenhardt, 1989; Miles et al. 2014) and explanationbuilding (Yin, 2018). We imported our data into NVivo qualitative data analysis (QDA) software and coded the text according to key themes derived from our research questions, our guiding frameworks, and the prior literature. We used the coded data to populate a table describing the constructs and parameters of the ecosystem framework, and to specify the platform and its components. Comparing cases, we inferred design rules for local Technovation chapters.

\section{Results}

The global Technovation ecosystem was characterized as a multisided platform, shown in Table 2, which maps the core ecosystem features to Technovation elements.

The ten sides are distinguished by their stakeholder group roles in the ecosystem. The actors on each side undertake unique activities that provide unique contributions. Some of the sides are official roles within the Technovation Girls competition, whereas others were identified through interviews with key personnel. For example, the "influencers and community leaders" side is not a role that an individual would formally register for; nonetheless, the actors on this platform side make an important contribution by helping new chapters gain legitimacy in their region.

Table 3 (placed at the end of this document) describes the multisided platform sides represented in Technovation. Sides 1 through 5 operate at the global level, while sides 6 through 10 operate within the local chapters. The local chapters are further decomposed into their own representations; however, collectively, all are connected through the global ecosystem.

The Technovation platform is driven by a process (Figure 1). The process is comprised of components, meaning the elements of the Technovation program that drive execution.

Some aspects of the process that we observed were tightly controlled by Technovation. For example, program registration and final project submission are mandated through their digital platform. Other platform transactions, such as curriculum delivery to students, were not specified globally. Further, only select platform sides had prescribed membership rules: volunteers, participants, and student ambassadors. Participation by other stakeholders was elective, based on self-alignment to a shared purpose.

Lastly, desired outcomes were focused on ensuring the program had a lasting, positive impact on participants

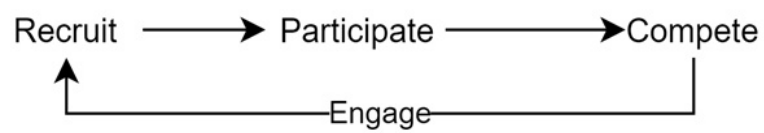

Figure 1. Technovation process 


\section{Ecosystems, Design, and Glocalization: A multi-level study of Technovation}

\section{Jasmine A. Shaw \& Steven M. Muegge}

and their future careers. Achieving these outcomes was the shared purpose (Moore, 2013) of the ecosystem.

\section{Local adaptation}

The ecosystem mapping approach was repeated for each of the six chapters. A notable result was that not all platform sides directly translated to the local level. For example, employees and the global ambassador were not present locally. On the other hand, the volunteers platform side was expanded to multiple, separate sides for regional ambassadors, mentors, judges, and instructors. New roles also emerged, such as schools and clubs. Furthermore, the particular stakeholders that comprised the platform sides, both individuals and organizations, varied between chapters.

The process platform was adopted consistently across all chapters. However, implementation of its components varied. For example, the Calgary chapter delivered program workshops (part of the "participate" process step) through secondary schools and the University of Calgary, while in Ottawa, workshops were delivered through corporate partners. For the "compete" process step, the Mexican chapters held individual live pitch events, whereas the Canadian chapters combined it into a nation-wide event.

Controls between platform sides varied based on requirements imposed by the regional ambassador or partner institutions. For example, one chapter required all male mentors to communicate with participants only through public channels. In another chapter, the regional ambassador was not permitted to directly match students with a mentor due to institutional liability it imposed on them.

Lastly, desired outcomes of the global ecosystem were translated to and shared among the local chapters. Certain chapters had additional, region-specific objectives, such as expanding the program throughout the province (Montréal), increasing engagement from both private and public sector volunteers (Ottawa), and raising awareness of career opportunities in nontraditional fields (Mérida).

\section{Design rules}

Consistent with Baldwin and Clark (2000), we identified and specified a design rule for each mandatory element of the various multisided platforms.

The process for specifying design rules within Technovation can be described in five steps: (1) identify mandatory program elements, (2) confirm the implicated actor is aware of a specific design rule (i.e., it is "visible information"), (3) express the rule using natural language, (4) identify one example for each design rule type consistent with the Baldwin and Clark (2000) definitions, and categorize the remaining design rules relative to the representative example, and (5) cross-reference design rules with program components to identify any gaps. Not all components necessarily have an associated design rule.

We present three examples of design rules corresponding to the three Baldwin and Clark (2000) types. First, architectural design rules define mandatory platform elements. They describe "who" and "what" is part of the system for it to function. One example is: Individuals must meet criteria for mentors to volunteer as a mentor for Technovation Girls. Second, interface design rules described the interactions (between individual sides as well as between the sides and the platform) and the interpretation and standardization of platform components. An example is: Teams must use one of the approved coding languages if they wish to be eligible for judging in the Technovation Girls competition. Lastly, integration rules ensure the program's consistency and efficacy. For example: Each Technovation Girls chapter must comply with the Technovation branding guidelines. Creating a familial resemblance among chapters has become particularly important strategically as they span over 50 countries, with a set of branding guidelines ensures that the regional instances remain part of the overall system.

\section{Discussion}

Our results imply three key insights about the architecture of global ecosystems.

The first insight concerns ecosystem anchors. Actors at the global level are largely focused on scaling up the Technovation program and increasing its global impact. This is accomplished through standardized processes developed by employees, strategic guidance by the board of directors, and international expansion led by the global ambassador. Global actors are thus anchored by shared purpose. Actors at the local level also share the objective of supporting girls in STEM, but they are anchored by a process (Figure 1). Local participation is bound to the Technovation Girls competition, whereas global participation is continuous and extends beyond a single competition cycle. However, the local chapters and global ecosystem are not detached entities following divergent paths. The non-profit organization is the keystone actor who mediates between these two levels 


\section{Ecosystems, Design, and Glocalization: A multi-level study of Technovation}

\section{Jasmine A. Shaw \& Steven M. Muegge}

and ensures alignment between high-level vision and strategy, and low-level program execution. Thus, we propose a multilevel anchor model (Figure 2).

The second insight concerns platform adaptation. The process steps served as a framework for local adaptation, which was performed at the component level. We observed both modularity and option value embedded in the platform. For example, the curriculum component is comprised of lessons (that is, individual modules), which the chapters reconfigured in various sequences. Further, the platform did not mandate participation in the compete and re-engage stages of the process. This created option value, whereby students and volunteers could participate as little or much in the program as they wanted. In the 2020 season, some teams did not submit their final project due to COVID-19; however, their participation at the beginning of the season still provided value (learning new skills, exposure to role models, etc.).

Designing a program that accommodates cultural, social, and economic variance of over 50 countries would be an impossible feat. Instead, Technovation has designed a platform with "modular mix-and-match flexibility [that] creates options" (Baldwin \& Clark, 2000). Based on Technovation's example, we propose that, in a global organization with regional instances, modularity facilitates localization.

The third insight concerns how design rules specified by Technovation create boundaries for local adaptation. Fixed parameters, such as limiting program participants to girls, have led to "a gain in efficiency through the elimination of cycles in the design process" (Baldwin \& Clark, 2000). That is, local chapters do not waste time on debating whether boys should be allowed to participate. Similarly, students developing their mobile app are limited to a predefined set of coding languages. While these fixed parameters constrain certain design decisions, their flexibility further increases the option value of the program: organizers may recruit girls from any part of their community, students may select any of the approved coding languages, and volunteers may come from a variety of professional backgrounds. This finding is consistent with the Meyer (2014) assertion that "glocalization supports local variations, but within legitimated boundaries" as well as with Baldwin and Clark (2016), according to whom "modules are distinct parts of the larger system, which can be designed and implemented independently as long as they obey the design rules".

Our results and discussion offer three contributions to theory and practice. Our first contribution was to specify the global Technovation ecosystem - including its actors, processes, and components -offering insights into a highly successful STEM outreach program. With increasing demands for diverse talent, it is imperative to learn from organizations with a proven track record of increasing young peoples' propensity to choose a career in STEM. Our second contribution was to explain about the impact of platform design on glocalization. We highlighted key architectural features of an existing process platform that enables local specialization. Lastly, our third contribution was expressing global

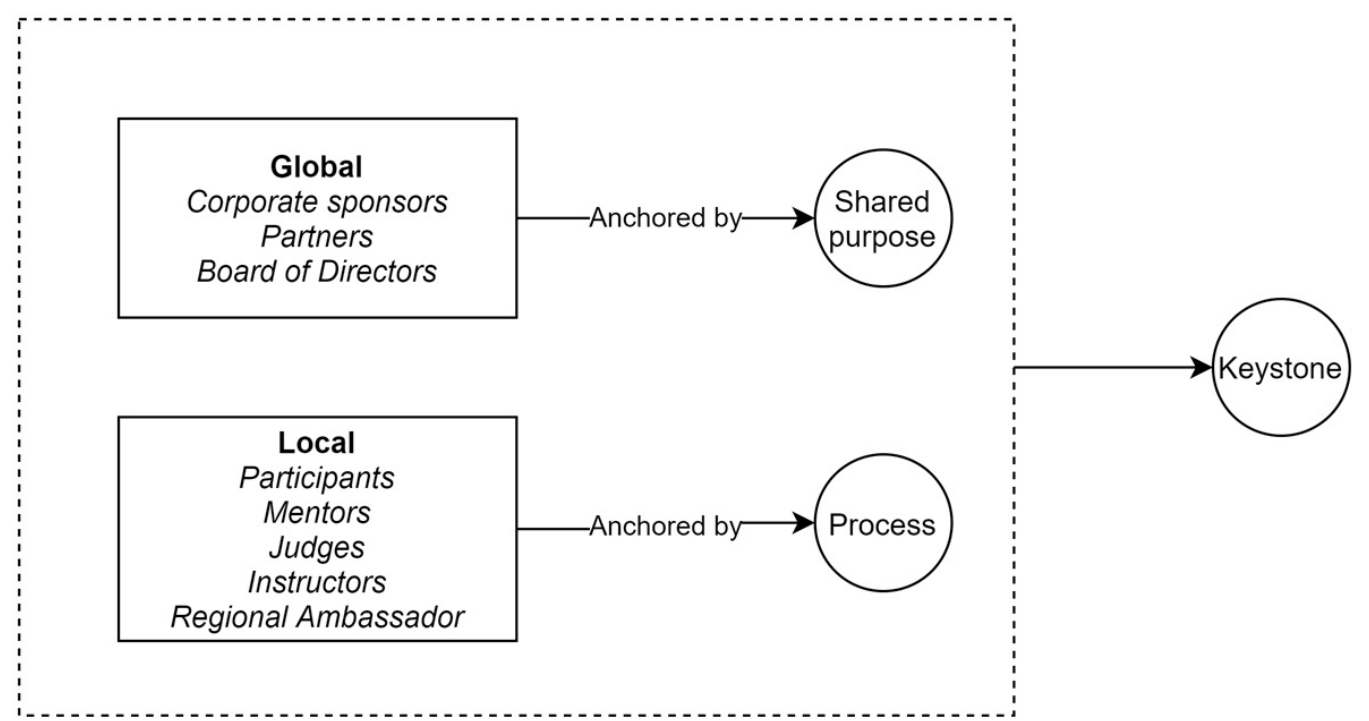

Figure 2. Multilevel anchor model of Technovation 


\section{Ecosystems, Design, and Glocalization: A multi-level study of Technovation}

\section{Jasmine A. Shaw \& Steven M. Muegge}

Technovation parameters as "design rules" — a novel approach in organizational studies. The five-step process defined in this study offers researchers and practitioners a method for characterizing interactions between global and local organizational entities, along with specifying those interactions as precise design rules.

We believe that the insights developed in this paper can spark further research. The process for deriving design rules can be validated in other organizational settings, such as a multinational corporation with local subsidiaries, or further extended within Technovation by examining additional regions beyond Canada and Mexico. Further, researchers should continue to explore multilevel ecosystems and refine the architectural propositions presented in this study, while developing a quantitative approach that expresses modularity and highlights the option value of process platforms.

Our research has three notable limitations. First, we focused on describing an established ecosystem. We did not observe the creation of either the Technovation process or its design rules. Thus, we may have missed out on deeper insights about how the design of a global ecosystem originated. Second, due to travel constraints imposed by COVID-19, we were not able to collect significant data in Mexico, which limited our understanding of how the three national chapters adapted the global platform. Lastly, we selected only a single framework to map Technovation. This inevitably created blind spots in our characterization of Technovation as an ecosystem, as we know that "each [framework provides] partial yet incomplete representations of the business ecosystem phenomena" (Muegge \& Mezen, 2017).

\section{Conclusion}

Business ecosystem research has expanded from product development, to technological innovation, to entrepreneurial ecosystems, which in turn create new ecosystems. We have further extended the applicability of the ecosystem construct in this paper to a missiondriven, global non-profit organization. By combining design rules with glocalization, we demonstrated that local instances of a global ecosystem are governed similarly to a complex system. Local instances share common components that can be adapted locally within the boundaries of global design rules. Scholars and practitioners can build on this linkage between design rules and glocalization to further explore the architecture of global ecosystems. 


\section{Ecosystems, Design, and Glocalization: A multi-level study of Technovation} Jasmine A. Shaw \& Steven M. Muegge

\section{Appendix}

Table 3. Platform sides of Technovation

\begin{tabular}{|c|c|c|c|c|}
\hline \# & Stakeholder group & Participants & $\begin{array}{l}\text { Contribution to the } \\
\text { platform }\end{array}$ & $\begin{array}{l}\text { Expected benefits from } \\
\text { the platform }\end{array}$ \\
\hline 1 & $\begin{array}{l}\text { Technovation } \\
\text { employees }\end{array}$ & Individuals & Knowledge & $\begin{array}{l}\text { Personal satisfaction } \\
\text { Salary }\end{array}$ \\
\hline 2 & Corporate sponsors & $\begin{array}{l}\text { Google } \\
\text { Adobe } \\
\text { Salesforce } \\
\text { (Organizations) }\end{array}$ & $\begin{array}{l}\text { Sponsorship } \\
\text { Credibility } \\
\text { Volunteers }\end{array}$ & $\begin{array}{l}\text { Employee } \\
\text { engagement } \\
\text { opportunity } \\
\text { Corporate social } \\
\text { responsibility } \\
\text { alignment }\end{array}$ \\
\hline 3 & Partners & TechWomen & $\begin{array}{l}\text { Support } \\
\text { Visibility }\end{array}$ & $\begin{array}{l}\text { Direct impact to their } \\
\text { programs }\end{array}$ \\
\hline 4 & Global ambassador & Individual & $\begin{array}{l}\text { Funding } \\
\text { Political and } \\
\text { industry support } \\
\text { Regional updates } \\
\text { and insights }\end{array}$ & $\begin{array}{l}\text { Scaling the program } \\
\text { globally }\end{array}$ \\
\hline 5 & Board of directors & $\begin{array}{l}\text { Technovation } \\
\text { CEO } \\
\text { Global } \\
\text { ambassdaor } \\
\text { Individuals } \\
\text { from sponsor } \\
\text { companies }\end{array}$ & $\begin{array}{l}\text { Voluntary } \\
\text { contribution of time } \\
\text { and expertise } \\
\text { Strategic guidance }\end{array}$ & $\begin{array}{l}\text { Maintaining corporate } \\
\text { engagement }\end{array}$ \\
\hline 6 & Volunteers & $\begin{array}{l}\text { Technology } \\
\text { professionals } \\
\text { Entrepreneurs } \\
\text { Teachers }\end{array}$ & $\begin{array}{l}\text { Time } \\
\text { Resources } \\
\text { Knowledge }\end{array}$ & $\begin{array}{l}\text { Personal satisfaction } \\
\text { Recognition }\end{array}$ \\
\hline 7 & Participants & $\begin{array}{l}\text { Girls aged } 10- \\
18\end{array}$ & $\begin{array}{l}\text { Time } \\
\text { Dedication }\end{array}$ & $\begin{array}{l}\text { Knowledge } \\
\text { Positive experiences } \\
\text { Increased confidence }\end{array}$ \\
\hline 8 & Parents & $\begin{array}{l}\text { Parents of } \\
\text { participants }\end{array}$ & Support & $\begin{array}{l}\text { Extracurricular } \\
\text { opportunity for their } \\
\text { child }\end{array}$ \\
\hline 9 & $\begin{array}{l}\text { Student } \\
\text { ambassadors }\end{array}$ & $\begin{array}{l}\text { Technovation } \\
\text { alumni }\end{array}$ & $\begin{array}{l}\text { Visibility } \\
\text { Recruitment }\end{array}$ & $\begin{array}{l}\text { Professional } \\
\text { development } \\
\text { opportunities }\end{array}$ \\
\hline 10 & $\begin{array}{l}\text { Influencers and } \\
\text { community leaders }\end{array}$ & & $\begin{array}{l}\text { Enabling regional } \\
\text { growth }\end{array}$ & $\begin{array}{l}\text { Supporting women in } \\
\text { STEM } \\
\text { Security, credibility, } \\
\text { and legacy of the } \\
\text { program }\end{array}$ \\
\hline
\end{tabular}




\section{Ecosystems, Design, and Glocalization: A multi-level study of Technovation}

\section{Jasmine A. Shaw \& Steven M. Muegge}

Table 4. Technovation Global components

\begin{tabular}{ll}
\hline Technovation Global component & Technovation Global element \\
\hline Program & Curriculum \\
& Digital platform \\
& World Summit pitch event \\
Regional ambassador resources & Resource page \\
& Webinars \\
& Technovation staff members (on-call support) \\
& Office hours \\
& Grants for regional programs \\
& Webinars \\
Volunteer resources & Resource page - mentors \\
& Resource page - judges \\
Participant resources & Support email \\
& Submission guidelines \\
& Rubric \\
Alumni program & Code checklist \\
Network & Professional development opportunities \\
& Alumni coordinator support role \\
& Slack channels \\
& Social media engagement \\
\hline
\end{tabular}

\section{References}

Adner, R. 2017. Ecosystem as Structure: An actionable construct for strategy. Journal of Management, 43(1): 39-58.

DOI: https://doi.org/10.1177/0149206316678451

Bailetti, T., \& Bot, S.D. 2013. An Ecosystem-Based JobCreation Engine Fuelled by Technology Entrepreneurs. Technology Innovation Management Review, 3(2): 31-40. DOI: https://timreview.ca/article/658.

Baldwin, C.Y., \& Clark, K.B. 2000. Design Rules: Volume 1: The power of modularity. Cambridge, MA: MIT Press. DOI: https://doi.org/10.7551/mitpress/2366.001.0001

Baldwin, C.Y., \& Clark, K B. 2006. The Architecture of Participation: Does code architecture mitigate free riding in the open-source development mode? Management Science, 52(7): 1116-1127. DOI: https://doi.org/10.1287/mnsc.1060.0546

Colombelli, A., Paolucci, E., \& Ughetto, E. 2019. Hierarchical and Relational Governance and the Life Cycle of Entrepreneurial Ecosystems. Small Business Economics, 52(2): DOI: https://doi.org/10.1007/s11187-017-9957-4

Drori, G.S., Höllerer, M.A., \& Walgenbach, P. (Eds.). 2014. Global Themes and Local Variations in Organization and Management. New York: Routledge. DOI: https://doi.org/10.4324/9780203139486
Eisenhardt, K.M. 1989. Building Theories from Case Study Research. Academy of Management Review, 14(4):

DOI: https://doi.org/10.5465/amr.1989.4308385

Eisenhardt, K.M., Graebner, M.E., \& Sonenshein, S. 2016. Grand Challenges and Inductive Methods: Rigor without rigor mortis. Academy of Management Journal, 59(4): 1113-1123. DOI: https://doi.org/10.5465/amj.2016.4004

Gawer, A., \& Cusumano, M.A. 2014. Industry Platforms and Ecosystem Innovation. Journal of Product Innovation Management, 31(3): 417-433. DOI: https://doi.org/10.1111/jpim.12105

Iansiti, M., \& Levien, R. 2004. Strategy as Ecology. Harvard Business Review, 82(3): 68-78. DOI: https://hbr.org/2004/03/strategy-as-ecology

Kapoor, R. 2018. Ecosystems: Broadening the Locus of Value Creation. Journal of Organization Design, 7(1): $1-16$.

DOI: https://doi.org/10.1186/s41469-018-0035-4

Meyer, J.W. 2014. Empowered actors, local settings, and global rationalization. Global Themes and Local Variations in Organization and Management, 429-440. DOI: ttps:// doi.org/10.4324/9780203139486-43

Meyer, R.E. 2013. Re-localization as Micro-Mobilization of Consent and Legitimacy. Global Themes and Local Variations in Organization and Management, 95-105. DOI: https://doi.org/10.4324/9780203139486-16 


\section{Ecosystems, Design, and Glocalization: A multi-level study of Technovation}

\section{Jasmine A. Shaw \& Steven M. Muegge}

Mezen, M. 2014. Business Ecosystems and New Venture Business Models: An exploratory study of participation in the Lead to Win job-creation engine. Master of Applied Science thesis, Technology Innovation Management, Carleton University, Ottawa, Canada. https://curve.carleton.ca/theses/31624.

Miles, M.B., Huberman, BA., \& Saldana, J. 2014. Qualitative Data Analysis: A Methods Sourcebook, 3rd edition, Thousand Oaks, CA: Sage Publications.

Moore, J.F. 1993. Predators and Prey: A New Ecology of Competition. Harvard Business Review, 73(3): 75-86. DOI: https://hbr.org/1993/05/predators-and-prey-anew-ecology-of-competition

Moore, J.F. 2006. Business Ecosystems and the View from the Firm, The Antitrust Bulletin, 51(1): 31-76. DOI: https://doi.org/10.1177/0003603x0605100103

Moore, J.F. 2013. Shared Purpose: A thousand business ecosystems, a connected community, and the future. Mountain View, CA: Create Space Publishing Platform.

Muegge, S.M. 2011a. Business Ecosystems as Institutions of Participation: A systems perspective on community-developed platforms. Technology Innovation Management Review, 1(2): 4-13. DOI: http://timreview.ca/article/495.

Muegge, S.M. 2011b. Business Ecosystems as Metaphor, Label, and Analogy. Presented at the Academy of Management 2011 Annual Meeting (AoM 2011, August 12-16, San Antonio, Texas, USA).

Muegge, S.M. 2013. Platforms, Communities, and Business Ecosystems: Lessons learned about technology entrepreneurship in an interconnected world, Technology Innovation Management Review, 3(2):

DOI: https://timreview.ca/article/655

5-15.

Muegge, S.M., \& Mezen, M. 2017. Business Ecosystems and New Venture Business Models: An exploratory study of participation in the Lead to Win job-creation engine. International Journal of Technology Management, $\quad 75(1 / 2 / 3 / 4)$ : 157-192. DOI: ttps://doi.org/10.22215/etd/2014-10280

Muegge, S.M., Bailetti, T., \& Sunna, A. 2018. A Design Perspective on Business Ecosystems: Intentional reuse of components. Proceedings of the ISPIM Innovation Forum 2018 (March 25-28, Boston, USA).

Natural Sciences and Engineering Research Council of Canada. 2017. Women in Science and Engineering in Canada.

https://www.nserc-crsng.gc.ca/_doc/ReportsRapports/WISE2017_e.pdf.

Parnas, D.L. 1972. On the Criteria to be Used in Decomposing Systems into Modules. Communications of the ACM, 15: 1053-1058. DOI: https://doi.org/10.1145/361598.361623
Radziwon, A., \& Bogers, M. 2019. Open Innovation in SMEs: Exploring inter-organizational relationships in an ecosystem. Technological Forecasting \& Social Change, 146: 573-587.

DOI: ttps://doi.org/10.1016/j.techfore.2018.04.021

Robertson, R. 1995. Glocalization: Time-Space and Homogeneity-Heterogeneity. Global Modernities: 2544.

DOI: https://doi.org/10.4135/9781446250563.n2

Rong, K., Hu, G., Lin, Y., Shi, Y., \& Guo, L. 2015. Understanding Business Ecosystem Using a 6C Framework in Internet-Of-Things Based Sectors. International Journal of Production Economics, 159: 41-55.

DOI: https://doi.org/10.1016/j.ijpe.2014.09.003

Simon, H.A. 1962. The Architecture of Complexity. Proceedings of the American Philosophical Society, 106(6): 467-482.

Sunna, A. 2016. Design of a Regional Venture-Creation Ecosystem by Reusing Components of another Ecosystem. Master of Applied Science thesis, Technology Innovation Management, Carleton University, Ottawa, Canada. https:// curve.carleton.ca/6b3d6c56-4cdf-451d-b8d5b6e7122e6dsf8

Yin, R.K. 2018. Case Study Research and Applications. 6th edition. Los Angeles, CA: SAGE Publications. 


\title{
Ecosystems, Design, and Glocalization: A multi-level study of Technovation
}

\section{Jasmine A. Shaw \& Steven M. Muegge}

\begin{abstract}
About the Authors
Jasmine Shaw is a Systems Engineer at General Dynamics Mission Systems - Canada where she designs cutting-edge aerospace technology. She completed a Master of Applied Science in Technology Innovation Management, and her thesis was at the intersection of design, globalization, and business ecosystems, specifically applied to global organizations that empower girls through technology entrepreneurship. As a new entrepreneur, she leverages her expertise in engineering, design, and business ecosystems to help women in STEM achieve their full career potential. She is an active member of the engineering community, serving on the Board of Directors at the Society of Women Engineers Ottawa, and volunteering for organizations such as Technovation.

Dr. Steven Muegge is an Associate Professor of Entrepreneurship at the Sprott School of Business at Carleton University. He teaches, conducts research, and supervises graduate students within Carleton's Technology Innovation Management (TIM) program, and actively promotes entrepreneurship and innovation within the broader community. Dr. Muegge leads an active research program in technology entrepreneurship and commercialization. One stream of current research examines non-traditional settings for innovation, including interconnected systems of business ecosystems, communities of users and developers, and industry platforms outside the control of any single company. A second stream examines the business models of technology entrepreneurs who create new companies and develop new products and services within these settings. Both streams are directly relevant to promoting economic prosperity for Canada and the National Capital Region, and to building differentiation and advantage for entrepreneurs and their companies.
\end{abstract}

Citation: Shaw, J.A. \& Muegge, S.M. 2021. Ecosystems, Design, and Glocalization: A multi-level study of Technovation. Technology Innovation Management Review, 11(5): 32-43.

http://doi.org/10.22215/timreview/1440 